\title{
DAMPAK GLOBALISASI PADA MASYARAKAT DAN SISTEM RELIGI DI KECAMATAN WATES KABUPATEN KEDIRI
}

\author{
*Suwarno ${ }^{1)}$, Sugeng Widodo ${ }^{2)}$, Teguh Pramono ${ }^{3)}$, Rizki Yudha Bramantyo ${ }^{4)}$ \\ 1) Program Studi Administrasi Publik Fakultas Ilmu Sosial dan Ilmu Politik \\ Universitas Kadiri, Indonesia \\ 2) Program Studi Administrasi Publik Fakultas Ilmu Sosial dan Ilmu Politik \\ Universitas Kadiri, Indonesia \\ 3) Program Studi Administrasi Publik Fakultas Ilmu Sosial dan Ilmu Politik \\ Universitas Kadiri, Indonesia \\ 4) Program Studi Ilmu Hukum Fakultas Hukum Universitas Kadiri, Indonesia
}

*Email Korespondensi : suwarno@unik-kediri.ac.id

\begin{abstract}
Abstrak
Fanatisme agama, maupun fanitisme sosial budaya tidak mampu membendung perkembangan dan persebaran teknologi yang dewasa ini sudah mengglobal di seluruh dunia, dan merasuk ke pelosok negeri, melompati lintas batas wilayah teritorial. Seluruh aktivitas kehidupan bahkan religi tanpa terkecuali terjangkiti oleh hal terseebut. Penelitian ini menggunakan pendekatan kualitatif, Adapun teknik yang digunakan untuk menentukan informan sebagai sumber data dengan teknik purposive, dan pengumpulan data dilakukan dengan penamatan mendalam dan wawancara mendalam, data yang telah terkumpul dan sudah melalui uji keabsahan data dianalisis dengan teknik analisis interaktif Milles dan Huberman. Hasil penelitian sebagai berikut : dalam pelaksanaan kegiatan religi masyarakat yang multi agamis maupun multi religi masing-masing dijiwai oleh sikap religius, supernatural, nilai-nilai religi, umat atau kesatuan sosial yang menganut sistem keyakinan tersebut (jamah) serta menggunakan media atau sarana dalam peribatan. Media peribadatan tersebut antara lain musholla, masjid, gereja, pure dan sejenisnya, sajadah, rukuh (bagi ummat muslim) dan masih banyak lagi. Pengaruh teknologi dan globalisasi tercermin dalam kehidupan sehari-hari, misalnya kentongan dan bedug digantikan oleh sound system (pengeras suara), Handphone menjadi media siar agama, disamping juga media bisnis atau komunikasi lain, demikian juga dengan kostum ibadah.
\end{abstract}

Kata Kunci: Sistem religi; Teknologi; Globalisasi 


\begin{abstract}
Religious and socio-cultural fanaticism have not been able to stem the development and spread of technology which has now become globalized throughout the world and has penetrated remote parts of the country, jumping across territorial borders. All activities of life and even religion are without exception infected by this. This study uses a qualitative approach.. The technique used to determine the informant as the data source was purposive technique, and data collection was carried out by in-depth observation and in-depth interviews, the data that had been collected, and had gone through the validity of the data were analyzed using the interactive analysis technique of Milles and Huberman. The results of the research are as follows: in the implementation of multi-religious and multi-religious community religious activities, each is imbued with religious attitudes, supernatural, religious values, people, or social entities that adhere to the belief system (jamah) and use media or means of involvement. The media for worship include prayer rooms, mosques, churches, purees, and the like, prayer mats, rukuh (for the Muslim ummah), and many more. The influence of technology and globalization is reflected in everyday life, for example, kentongan and drum replaced by a sound system (loudspeaker), cellphones become a medium for broadcasting religion, as well as other business or communication media, as well as religious costumes.
\end{abstract}

Keywords: Religious system; Technology; Globalization

\title{
PENDAHULUAN
}

Sistem religi dalam setiap agama terus dijalankan oleh ummatnya masing-masing sebagai bentuk ketaqwaan, kepasrahan, dan atau keikhlasan bagi yang mengerjakan. Namun demikian tidak bisa dipungkiri bahwa perkembangan teknologi maju dengan pesat sehingga dalam waktu yang relatif singkat sudah berkembang dan menguasai dunia. Hal tersebut sesuai dengan prinsip ilmu pengetahuan dan budaya manusia untuk selalu mencari dan menemukan teknologi yang dapat memberikan manfaat atau keuntungan terhadap manusia itu sendiri. Oleh karena itu persebaran kemajuan teknologi berlangsung cepat dan melintasi lintas batas teritorial suatu negara.

Persebaran pemanfaatan kemajuan teknologi tersebut tidak hanya hanya di kalangan militer saja, melainkan hampir seluruh bentuk kehidupan manusia terpengaruhi, demikian juga dengan religi atau agama. Dalam hal religi atau agama bukan sudut ajaran agamanya atau ajaran religinya melainkan berbagai media atau sarana ibadah keagamaan sudah sangat terpengaruhi oleh kemajuan teknologi. Siar agama dewasa ini tidak harus tatap muka, melainkan dengan memanfaatkan Hand phone berbagai informasi tentang keagamaan dapat tersampaikan. 
Nilai-nilai kemasyarakatan, norma adat dewasa ini sudah banyak yang mengalami perubahan atau minimal tergeser dari semula. Hal tersebut sangat sulit dihindari, sebab hampir seluruh aktivitas kehidupan manusia terpengaruh oleh arus globalisasi dan kemajuan teknologi. Oleh karena itu banyak nilai-nilai tersebut yang harus menyesuaikan dengan perkembangan dan kemajuan tersebut, yang penting tidak sampai merubah hakikat dari nilai-nilai sosial budaya dari masyarakat tersebut. Kondisi tersebut sebagaimana dideskripsikan oleh Muttaqin (2014) Globalisasi bersifat utilitarian yang menggerus lokalitas masyarakat dunia. Sebagai sebuah keniscayaan, globalisasi tidak bisa ditolak oleh warga dunia manapun, termasuk di dalamnya adalah warga negara yang beragama.

Kuatnya keyakinan dan iman setiap ummat pemeluk agama tidak sampai tergoyahkan oleh arus globalisasi, justru berbagai perbedaan berbagai agama dan religi yang ada serta perbedaan suku bangsa tidak menjadikan timbulnya konflik diantara mereka. Hal tersebut sudah tertanamkan oleh penyebar agama terdahulu serta sudah tertanamnya nilai-nilai kerukunan ummat beragama tersebut oleh pendahulu. Hal tersebut sebagaimana dijelaskan oleh I Made Pageh dalam tulisannya bahwa proses pembentukan multikulturalisme telah dilakukan sejak dulu Pertanyaannya adalah bagaimana Dampak Globalisasi pada masyarakat dan sistem religi di Kecamatan Wates Kabupaten Kediri.

\section{TINJAUAN PUSTAKA}

Emile Durkheim dalam Suwarno (2007) menjelaskan bahwa masyarakat bukanlah sekadar jumlah total individu-individu, dan bahwa sistem yang dibentuk oleh bersatunya mereka itu merupakan suatu realitas spesifik yang memiliki karakateristiknya sendiri. Bagi Durkheim, masyarakat, dan prinsip asosiasi adalah yang utama, dan arena masyarakat secara tak terbatas mengungguli individu dalam ruang dan waktu, maka masyarakat berada pada posisi menentukan cara bertindak dan berpikir terhadapnya.

Lebih jauh konsep Durkheim yang dijelaskan kembali oleh Peter Beilharz (2005:101) Terdapat dua problem utama di dalam zaman yang terus berubah ini, yaitu yang pertama adalah mengenai otonomi sosial sebagai level realitas yang khas dan tidak dapat direduksi menjadi wilayah-wilayah individu, dan kedua mengenai krisis modernitas yaitu menyebabkan putusnya ikatan-ikatan sosial tradisional karena industrialisasi, dan 
individualisme. Dua problem tersebut saling berkaitan, yang percaya bahwa problemproblem yang disebabkan runtuhnya tatanan tradisional hanya akan dapat diatasi berdasarkan pada pemahaman ilmiah.

Dewasa ini, kita hidup di era globalisasi, jadi masyarakat yang ada di suatu wilayah merupakan bagian dari masyarakat dunia, demikian juga dengan kondisi sosial, budaya, ekonomi, politik termasuk juga pemerintah dan sistem pemerintahan, (Martin Albrow, 2001:149). Lebih Jauh Martin Albrow menjelaskan, dalam politik global yang didominasi oleh Amerika Serikat dan negara-negara kaya, mereka berkeinginan membuat masyarakat, kolektivitas, networks dan segala identitas dalam mentransformasikan pemerintah ke dalam pemerintahan. Hal ini akan menimbulkan difusi yang luas dari kebebasan dan tanggungjawab bersama di setiap kelompok masyarakat.

Kondisi masyarakat sebagaimana yang dikemukakan oleh (Muzaqi et al., 2020) jika dikaji lebih mendalam adalah masyarakat sebagai suatu jaringan yang mana satu sama lain saling membutuhkan, saling berpengaruh, saling berhubungan, ibarat sebagai suatu system. Jika salah satu system tersebut tidak jalan maka akan berdampak pada system yang lain. Ini berarti tidak ada lagi istilah local, tidak ada lagi pembatas wilayah dalam dunia sosial, semua bias ditembus dalam dunia maya hanya menggunakan teknologi komunikasi. Tidak ada lagi local wisdom yang ada adalah budaya internasional atau internasional culture. Padahal kehidupan masyarakat itu bersuku-suku dan berbangsa-bangsa dan itu justru menunjukan keberagaman keberbedaan dalam kebersamaan untuk mengelola planet bumi yang kita tempati.

Istilah globalisasi mengacu pada 3 konsep berbeda : 1) interdependence atau saling ketergantungan : teknologi dan komunikasi, kebijakan makro ekonomi negara dapat bertindak sendiri, tanpa mengambil resiko. Ini merupakan suatu aspek dari berbagai kaum, dan masyarakat sebagai jaringan, (Polnaya \& Darwanto, 2015) atau era hubungan, (Sandriharmy, 2010) ekonomi, pengelompokan struktural dan regional sebagai suatu organisasi global. 2) globalitas : sistem finansial kapitalis, penduduk dunia, trend kesehatan, transportasi udara, sumber air, hutan, perubahan iklim, pasar modal, dan respon terhadap masalah ini selalu lokal, (Ruhil, 2017). 3) budaya, ekonomi, lingkungan. 
Dalam perkembangan peradaban manusia, tidak semua kejadian dapat dijelaskan dengan logika. Pada hal yang demikian manusia mulai menyadari ada sesuatu yang menyebabkan manusia hidup, yaitu konsep ruh, emosi jiwa, emosi keagamaan. Sebagaimana dideskripsikan oleh Taylor dalam Koentjaraningrat (2005 : 194-195) tentang konsep ruh dan kehudupan manusia dalam masyarakat. Sementara itu religi merupakan bagian dari kebudayaan dan sistem religi merupakan suatu agama bagi pemeluknya, misalnya sistem religi (Koentjaraningrat, 2000 : 144).

Tulisan Koentjaraningrat tentang konsep religi merupakan bagian dari kebudayaan, banyak dipengaruhi oleh tulisan Emile Durkheim dalam Suwarno, (2007) "Les Formes Elementaires de la Vie Religieuse”, yang menyatakan bahwa setiap religi merupakan suatu sistem yang terdiri dari lima komponen, yaitu: (1) Emosi keagamaan yang menyebabkan manusia itu bersikap religieus; (2) Sistem keyakinan yang mengandung segala keyakinan serta bayangan manusia tentang sifat-sifat Tuhan, tentang wujud dari alam gaib (supernatural), serta segala nilai, norma dan ajaran dari religi yang bersangkutan; (3) Sistem ritus dan upacara yang merupakan usaha manusia untuk mencari hubungan dengan Tuhan, dewa-dewa atau makhluk-makhluk halus yang mendiami alam gaib; (4) Umat atau kesatuan sosial yang menganut sistem keyakinan tersebut dalam sub 2 dan yang melaksanakan sistem ritus dan upacara dalam sub 3; (5) Alat-alat fisik yang digunakan dalam ritus dan upacara keagamaan.

Dalam Agama Islam, setiap mengerjakan ibadah keagamaan seluruh aurat harus tertutup. Alat penutup aurot itu dewasa ini adalah kain yang dibuat model dan menjadi mode pakaian sesuai dengan budaya dari masing-masing bangsa. Bangsa Indonesia dikenal dengan kain sarung, baju koko, songkok atau kopyah dan bagi kaum perempuan kain yang menutupi aurot mereka. Berbeda lagi bagi bangsa-bangsa di Timur Tengah, dan berbeda pula bagi bangsa lain, namun terdapat kesamaan fungsi yaitu untuk menutupi aurot mereka, kondisi ini terus berkembang sesuai dengan perkembangan teknologi.

Terkait dengan cultur dan sistem religi Koentjaraningrat menjelaskan bahwa terdapat 5 komponen penting, yang satu dengan yang lain saling terkait, saling mempengaruhiu, saling menjadi sebab dan akibat. Ke lima komponen tersebut adalah kelompok keagamaan, sistem keyakinan, sistem upacara, emosi dan peralatan keagamaan. 
Salah satu komponen tersebut tidak berjalan sendiri, namun ke lima komponen tersebut semua berjalan berirama sesuai dengan irama emosi mereka.

Sistem keyakinan mengandung keyakinan tentang sifat-sifat Tuhan, tentang wujud dari alam gaib, tentang hakekat hidup dan maut, dan tentang wujud dari dewa-dewa dan makhluk halus. Sistem keyakinan erat berhubungan dengan ritus dan upacara, dan menentukan tata urut dari unsur-unsur, rangkaian acara serta peralatan yang dipakai dalam upacara. Sistem ritus dan upacara melambangkan konsep-konsep yang terkandung dalam sistem keyakinan. Sistem upacara merupakan wujud kelakuan (behavioral manifestation) dari religi.

\section{METODE PENELITIAN}

Dalam melakukan penelitian ini menggunakan pendekatan kualitatif, hal tersebut dengan pertimbangan karakter permasalahan yang hanya bisa dijawab dan diperoleh datanya dengan pendekatan tersebut. Adapun alasan penelitian dilakukan di Kecamatan Wates adalah pertama faktor hiterogenitas masyarakat dan agama serta kepercayaan yang ada di masyarakat kecamatan Wates, walaupun di pedesaan. Kedua, walaupun demikian kondisi masyarakatnya tidak pernah terjadi berbagai konflik.

Agar dapat dikumpulkan data sesuai dengan permasalahan maka digunakan teknik penentuan informan dengan teknik purposive, yaitu teknik penentuan informan dengan pertimbangan-pertimbangan tertentu, yaitu penguasaan dan kedalaman informasi yang dikuasai, antara lain tokoh masyarakat dengan berlatar belakang agama dan kepercayaan masing-masing satu, tokoh pendidikan di daerah tersebut 2 orang, tokoh pemuda dengan latar belakang agama dan kepercayaan masing-masing 1, kepala desa (3 orang).

Teknik yang digunakan untuk mengumpulkan data dengan teknik observasi, wawancara, dan dokumentasi. Hal tersebut digunakan agar data yang dikumpulkan saling melengkapi. Data yang telah terkumpul dilakukan uji validasi data atau keabsahan data dengan teknik triangulasi data. Selanjutnya dianalisis dengan teknik analisis interaktif dari Milles dan Huberman. 


\section{HASIL DAN PEMBAHASAN}

Masyarakat di wilayah Kecamatan Wates Kabupaten Kediri mayoritas bekerja sebagai petani, hanya sebagian kecil yang bekerja di sektor swasta (perdagangan dan jasa). Kehidupan sosial budaya mereka diwarnai oleh jenis pekerjaan dan nilai-nilai adat dan kultur yang berlaku di daerah tersebut. Harmonisasi kehidupan menjadi prioritas utama dalam setiap aktivitas yang dilakukan oleh masyarakat. Perbedaan pendapat, sikap dan perilaku tidak sampai mencuat ke permukaan, hal ini karena adanya peran serta pengaruh tokoh masyarakat yang ada disamping juga karena adanya kearifan lokal yang ada. Kearifan lokal yang dimaksud juga menjadi acuan dalam setiap aktivitas yang dilakukan oleh masyarakat. Oleh karena itu, kehidupan masyarakat berjalan seperti biasa, yaitu rukun, damai, tentram dan bersahaja (sederhana). Hal tersebut ditandai dengan tidak pernah terjadi konflik horizontal diantara mereka. Adat istiadat, norma dan kehidupan umat beragama masing-masing berjalan sesuai dengan nilai-nilai adat dan norma serta agama yang dianut. Sebagian besar masyarakat Kecamatan Wates beragama Islam, kemudian Kristen, dan sisanya yang lain. Setiap pemeluk agama mengerjakan peribadatan dengan khusyuk (khidmat) sebagai ungkapan emosi keagamaan mereka.

Dewasa ini tidak ada kehidupan masyarakat yang tidak terpengaruh oleh kemajuan teknologi dan globalisasi. Demikian juga dengan kehidupan masyarakat di Kecamatan Wates Kabupaten Kediri. Nilai-nilai sosial budaya, kearifan lokal yang ada dewasa ini sedikit banyak mau tidak mau mengalami pergeseran sebagai dampak dari pemakaian teknologi (komunikasi oleh masyarakat), sebagai contoh pertemuan antar warga maupun dalam pemerintahan desa tidak selamanya harus tatap muka, namun bisa juga dilakukan dengan teknologi komunikasi (daring).

Selanjutnya dibidang pekerjaan juga banyak terpengaruh oleh kemajuan teknologi sebagai contoh: dulu mereka membajak sawah dengan bantuan sapi atau kerbau, namun dewasa ini petani membajak sawah ataupun ladang dengan menggunakan traktor. Hampir setiap orang tidak terlepas dari kepemilikan Handphone, baik itu sebagai sarana komunikasi kekeluargaan, bisnis , pengembangan usaha, hiburan maupun komunikasi lain

Kehidupan antar ummat beragama berlangsung harmonis, saling menghormati, saling bertoleransi, hal ini sudah ditanamkan oleh pendahulu mereka dalam membangun 
kehidupan bermasyarakat yang damai dan tentram. Berbagai sarana peribadatan dibangun sebagai sarana ibadah. Bentuk, aksesoris, dan penerangan mencerminkan kehidupan modern. Dulu panggilan sholat menggunakan kenthongan atau bedhug, namun dewasa ini sudah menggunakan sound system (pengeras suara), panggilan waktu menggunakan arloji, sudah tidak lagi berpatokan pada matahari. Handphone juga sebagai media siar agama, banyak pengajian, atau materi-materi yang bernuansa keagamaan termuat didalamnya. Bahkan Alqur'an juga termuat di dalamnya. Banyak para ustad maupun Ustadzah melakukan siar agama melalui handphone. Seluruh kehidupan masyarakat sudah terpengaruh oleh teknologi modern, baik itu dalam hal pekerjaan, transportasi, sosial, ekonomi, budaya maupun politis dan keagamaan.

Begitu besar pengaruh kemajuan teknologi yang mengglobal ke seluruh dunia, hampir segala sendi kehidupan baik itu sosial, ekonomi, budaya, politik, pendidikan, dan pergaulan serta peribadatan keagamaan dan religi mengalami pergeseran sebagai bentuk adaptasi manusia dengan teknologi yang berkembang. Perlu dicatat bahwa pergeseran atau perubahan yang terjadi pada kehidupan keagamaan hanya sebagai media peribadatan namun pada sisi ajaran dan syariat keagamaan tidak boleh berubah apapun itu alasannya.

Pada era globalisasi, seluruh sendi-sendi kehidupan bermasyarakat dan beragama serta berbangsa dan bernegara dipengaruhi oleh kemajuan teknologi. Dampak kemajuan teknologi yang dirasakan tidak hanya pada sektor fisik saja namun merambah pada aspek mindset berpikir saja namun sampai pada sikap dan perilaku sehari-hari. Hal terseebut tampak pada peran dan pengaruh adat istiadat, norma dalam masyarakat yang mengatur perilaku sosial masyarakat (lokal) banyak mengalami pergeseran atau mungkin sedikit demi sedikit musnah terkikis oleh kemajuan teknologi yang mnegandalkan pada rasio dan fakta. Hukum adat terkikis oleh hukum formal, hal ini karena perilaku masyarakat sendiri yang cenderung tidak lagi menghormati hukum adat yang dianggapnya irrasional dan tidak memiliki kekuatan materiil dihadapan ketentuan pemerintahan dan hukum.

Keragaman dan perbedaan dalam masyarakat tidak hanya berarti perbedaan antara individu, acuannya adalah pemerataan harapan hidup atau perjuangan dengan sesama. Perbedaan membentuk kewarganegaraan, jenis kelamin, agama, suku justru memperkuat konsekuensi baik individu maupun sosial. Pemerintahan, perusahaan, dan individu 
membentuk acuan kolektif pada orang-orang yang sama identitasnya. Identitas secara potensial menjadi situs sentimen kolektif yang dapat dimobilisasi untuk tujuan politik, ekonomi, dan sosial budaya.

Begitu, identitas sebagai situs solidaritas, maka masyarakat nasional tidak lagi menyediakan kerangka ekslusif untuk mobilisasi politis. Komitmen bisa juga tidak hanya dilekatkan pada penduduk di era lokal tetapi juga pada pekerjaan, kepercayaan, gaya hidup, tak satupun yang ditetapkan oleh batas wilayah masyarakat nasional. Untuk identitas, bangsa merupakan penyedia layanan lokal, sedangkan masyarakat adalah nasional.

Ada konfigurasi lain dari era global, masyarakat bangsa adalah seperangkat hubungan kebudayaan, ekonomi politik dan teknologi antara manusia secara terpisah, tetapi secara efektif menunjukkan sebagai suatu negara. Sekolah, pabrik, kota di dalam kondisi global, mereka butuh otonomi baru, sehingga wilayah seperti lembah silikon, membutuhkan identitas global sebagai "hot spot" ekonomi. Hubungan internal mereka lokal, sedangkan hubungan eksternalnya global. Manuel Castells (1996) memandang jaringan kerja sebagai fitur penentu masyarakat kontemporer. Disamping identitas sebagai perpecahan individu, secara kontemporer, identitas sebagai hubungan potensial, kekuatan sosial potensial dalam konteks pemerintahan. Ketegangan antara kekuatan lokal dengan prinsip-prinspi universal ini mendorong perubahan institusional.

Berdasarkan keragaman sosial, pemikiran kembali tentang masyarakat dan pengaruh kemajuan teknologi yang berdampak pada pembaharuan dan berakibat pada perubahan atau minimal pergeseran sosial memerlukan peran dan uluran kebijakan pemerintah untuk mengelola hal tersebut. Hal ini penting agar pergeseran atau perubahan sosial yang terjadi tidak menjadi liar namun masih berada di dalam koridor karakter bangsa dan negara Indonesia. Beberapa bentuk campur tangan pemerintah atas globalisasi dan kebebasan kehidupan masyarakat dengan dikeluarkannya kebijakan undang-undang Informasi dan transaksi Elektronik (ITE), undang-undang kebebasan pers dan Undangundang Dasar 45.

Menurunnya kepatuhan anggota masyarakat di dalam hukum adat, norma yang berlaku di masyarakat secara sadar atau tidak sadar karena pengaruh globalisasi dan 
masyarakat Indonesia menjadi bagian dari masyarakat dunia. Namun demikian tidak selamanya globalisasi tersebut mejadi bersifat negatif, tidak sedikit pengaruh kemajuan teknologi tersebut yang berdampak pada kemajuan bangsa dan negara. Salah satu contoh dari hal tersebut adalah kemajuan di sektor pendidikan baik itu pendidikan formal maupun sistem pendidikan di kalangan pesantren yang tetap menjunjung tinggi kearifan lokal.

\section{KESIMPULAN DAN SARAN}

Emosi keagamaan merupakan suatu getaran yang menggerakan jiwa manusia. Emosi keagamaan dapat dirasakan oleh setiap orang. Oleh karena itu setiap orang akan bersujud (melakukan shalat dengan penuh khidmat), berdo'a seorang diri maupun kelompok (berjama'a) selalu berupaya untuk khidmat (kusyuk). Sistem keyakinan dalam suatu religi dijiwai oleh emosi keagamaan, tetapi sebaliknya emosi keagamaan juga bisa dikobarkan oleh sistem kepercayaan. Media untuk menjalankan keyakinan atau sistem religi terpengaruh oleh teknologi dan globalisasi, demikian juga dengan siar agama.

\section{REFERENSI}

Albrow, Martin. 2001. Governance in 21 Century : Society as Sosial Diversity : The Challenge for Governance in the Global Age. Woodrow Wilson International Center for Scholars, United States and University of Surrey Roehampton, United Kingdom.

Beilharz, P. 2005. Teori-Teori Sosial, Observasi Ktritis Terhadap Filsof Terkemuka, Pustaka Pelajar, Yogyakarta.

Castells, Manuel. 1996. The Rise of the Network Society, Oxford: Blackwell.

Koentjaraningrat, 2010. Kebudayaan, Mentalitas dan Pembangunan, Gramedia Pustaka Utama, Jakarta.

Mulgan, Geoff. 1998. Connexity: Responsibility, Freedom, Businessand Power in the New Century. London: Vintage.

Muttaqin, A. 2014. Eksistensi Agama Dalam Era Globalisasi. KOMUNIKA: Jurnal Dakwah Dan Komunikasi, 8(1), 41-59.

Muzaqi, A. H., Pratama, M. R., \& Widodo, S. 2020. Strategi Peningkatan Kesejahteraan Sosial Penyandang Disabilitas Netra Melalui Kebijakan Ingklusif. Journal 
Publicuho, 3(3), 381-393.

Polnaya, G. A., \& Darwanto. 2015. Pengembangan Ekonomi Lokal Untuk Meningkatkan Daya Saing Pada Ukm Ekonomi Kreatif Batik Bakaran Di Pati, Jawa Tengah. Jurnal Bisnis Dan Ekonomi, Vol 22, No 1 (2015)

Robertson, R. 1992. Globalization, London: Sage.

Ruhil, R. 2017. Millennium Development Goals to Sustainable Development Goals: Challenges in the Health Sector. Journal Description International Studies, Vol. 52(1-4), 118-135.

Sandriharmy, K. 2010. The Role of Law in Solving the Banking Crisis in Indonesia (second edi). PT. Rajagrafindo Persada.

Suwarno. 2007. Disertasi : Perubahan Sosial Masyarakat Bakumpai Kabupaten Katingan Kalimantan Tengah. Program Pascasarjana UNMER. Malang. 